\title{
Estilos de Aprendizagem: evidências a partir de uma revisão sistemática da literatura
}

\author{
Learning Styles: evidence from a systematic
}

literature review

\author{
Elisangela Aparecida Bulla IKeshoji (iD ${ }^{a}$
}

Adriana Aparecida de Lima TerÇariol(iDob

\section{Resumo}

Entende-se que o professor, ao conhecer seu estilo de ensino, pode alinhar de maneira mais adequada as estratégias de ensino, para contribuir com a aprendizagem significativa do aluno, segundo o seu estilo de aprendizagem. Nesse sentido, o objetivo principal deste artigo foi evidenciar como os estilos de aprendizagem contribuem com processo de ensino na educação básica e no ensino superior. Visando alcançar o objetivo proposto, realizou-se uma pesquisa exploratória, a partir de um levantamento sistemático da literatura, com o intuito de se buscar produções nas bases de dados do Portal de Periódicos da CAPES, ProQuest e SCOPUS, que focam os estilos de aprendizagem segundo a teoria de Alonso, Gallego e Honey (1994). Os critérios de inclusão adotados foram: teoria de Alonso, Gallego e Honey; sem parâmetro quanto ao período de publicação; artigos e/ou anais de eventos; independentemente do qualis do periódico e/ou evento. Portanto, a identificação dos estilos de aprendizagem pode ser um ponto de partida para a sistematização do complexo processo de ensino e de aprendizagem. Entende-se que o reconhecimento desses estilos pode contribuir com a minimização das lacunas existentes no processo de ensino e aprendizagem, uma vez que podem ser utilizados no contexto escolar para se abordar o currículo, nos diferentes níveis de ensino, de forma mais efetiva e significativa.

\footnotetext{
a Instituto Federal de Educação, Ciência e Tecnologia de São Paulo, Câmpus Birigui, Birigui, SP, Brasil. Mestre em Educação, e-mail: elisangela.bulla@gmail.com

b Universidade Nove de Julho (UNINOVE), São Paulo, SP, Brasil. Doutora em Educação, e-mail: atercariol@gmail.com
} 
Palavras-chave: Estilos de Aprendizagem. Estilos de Ensino. Estratégias de Aprendizagem. Estratégias de Ensino.

\begin{abstract}
It is understood that the teacher, knowing his teaching style, can better align the teaching strategies to contribute to the student's significant learning, according to his learning style. In this sense, the main objective of this article was to highlight how learning styles contribute to the teaching process in basic and university education. In order to achieve the proposed objective, an exploratory research was carried out, based on a systematic survey of the literature, in order to search for productions in the databases of the CAPES, ProQuest and SCOPUS Journal Portal, that focus on learning styles according to the theory of Alonso, Gallego and Honey (1994). The inclusion criteria adopted were: Alonso, Gallego and Honey theory; without parameter regarding the publication period; articles and / or annals of events; regardless of the journal's qualifications and / or event. Therefore, the identification of learning styles can be a starting point for the systematization of the complex teaching and learning process. It is understood that the recognition of these styles can contribute to minimize the gaps in the teaching and learning process, once they can be used in the school context to approach the curriculum, at different levels of education, in a more effective and meaningful way.
\end{abstract}

Keywords: Learning Styles. Teaching Styles. Learning Strategies. Teaching Strategies.

\title{
Resumen
}

Se entiende que el maestro, al conocer su estilo de enseñanza, puede alinear mejor las estrategias de enseñanza, para contribuir al aprendizaje significativo del estudiante, de acuerdo con su estilo de aprendizaje. En este sentido, el objetivo principal de este artículo fue destacar cómo los estilos de aprendizaje contribuyen al proceso de enseñanza en la educación básica y la educación superior. Para lograr el objetivo propuesto, se llevó a cabo una investigación exploratoria, basada en una encuesta sistemática de la literatura, con el fin de buscar producciones en las bases de datos de CAPES, ProQuest y SCOPUS Journal Portal, que se centran en los estilos de aprendizaje según la teoría de Alonso, Gallego y Honey (1994). Los criterios de inclusión adoptados fueron: teoría de Alonso, Gallego y Honey; sin parámetro con respecto al período de publicación; artículos y/o anales de eventos; independientemente de las calificaciones y/o eventos de la revista. Por lo tanto, la identificación de los estilos de aprendizaje puede ser un punto de partida para la sistematización del complejo proceso de enseñanza y aprendizaje. Se entiende que el reconocimiento de estos estilos puede contribuir a minimizar las brechas en el proceso de enseñanza y aprendizaje, ya que pueden usarse en el contexto escolar para abordar el plan de estudios, en diferentes niveles de educación, de una manera más efectiva y significativa. 
Palabras clave: Estilos de Aprendizaje. Estilos de Ensenañza. Estrategias de aprendizaje. Estrategias de enseñanza.

\section{Introdução}

O professor, como articulador do processo de construção do conhecimento, precisa criar e oportunizar o acesso à uma variedade de recursos e/ou ferramentas pedagógicas em seu contexto de atuação, mais especificamente em sua sala de aula, seja de forma presencial ou on-line, sempre visando os objetivos de aprendizagem a serem alcançados (SILVA, 2015). O conhecimento é compreendido neste artigo como sendo resultado obtido da relação existente entre perguntas e respostas, visto que, "para o espírito científico qualquer conhecimento é uma resposta a uma pergunta. Se não há pergunta não pode existir conhecimento científico. Nada se dá; tudo se constrói” (BACHELARD, 1989, p. 189). Lembrando que, “o conhecimento que não é apresentado junto com as condições de sua determinação precisa, não é conhecimento científico. O conhecimento geral, é quase fatalmente conhecimento vago" (BACHELARD, 1996, p. 90).

Todavia, quando o conhecimento científico é construído, as respostas às questões são dadas para o objeto em estudo, mas "estas ganham forma autônoma e podem ser separadas e deslocadas no espaço e no tempo das perguntas que lhe deram origem e dos processos que permitiram a sua elaboração" (GAMBOA, 2009, p. 12). No momento em que é perdida essa relação dinâmica “entre pergunta resposta, transformando-se num saber (resposta já dada, já dita) pronto para ser apropriado, formatado, sistematizado, utilizado e acumulado pela humanidade" (GAMBOA, 2009, p. 12-13), entende-se que se torna conhecimento geral, que é então apropriado pela humanidade e transformado na escola.

Segundo Gamboa (2009, p. 13) é essencial "[...] diminuir o distanciamento entre as perguntas geradoras do conhecimento e as respostas acadêmicas congeladas nos saberes escolares e amplamente divulgadas como informações ou saberes, através dos sistemas informatizados, livros e materiais didáticos e conteúdos curriculares [...]". Nesse sentido, a aprendizagem ocorre a partir das ações pedagógicas que integram diversos recursos. Sob esse contexto, proporciona-se 
condições dos alunos mobilizarem ou desenvolverem suas estratégias de aprendizagem para, então, fazerem novas perguntas às respostas já dadas.

“A aprendizagem pode ser definida a partir do comportamento do aluno (visível), bem como a partir das estruturas de pensamento (não visíveis) que sustentam esse comportamento" (PERRAUDEAU, 2006, p. 11 apud SILVA, 2015, p. 25). Tais estratégias são sequências integradas de atividades que o aluno pode mobilizar, para facilitar a compreensão da informação a ser processada nas estruturas cognitivas (BECKER, 2013) e como conjunto de dados, que ao ser processada e articulada cognitivamente pelo aluno, lhe oferece condições de reelaborar e construir novas perguntas para as respostas até então encontradas.

Sendo assim, a aprendizagem pode ser considerada como "qualquer processo que, em organismo vivo, leve a uma mudança permanente em capacidade e que não se deva unicamente ao amadurecimento biológico ou ao envelhecimento" (ILLERIS, 2007 apud ILLERIS, 2013, p. 16). Por isso, considera-se que no processo de ensino, o professor pode contribuir para que o aluno identifique e descubra suas estratégias para aprender. Nesse sentido, destaca-se aqui a importância do professor saber qual é o seu próprio estilo de ensinar, de modo que possa optar e/ou desenvolver outros estilos que venham ao encontro daquele que o aluno necessita para aprender. Sabe-se que, "a dificuldade em planejar, tirar dúvidas, fazer questionamentos, impede-os de desenvolver estratégias de aprendizagem diferentes das que o professor utiliza em sala de aula" (FERREIRA, 2007, p. 4).

Nesse processo de ensino e de aprendizagem entende-se que o diálogo deve ser bastante aberto entre professor e aluno, visto que o professor precisa ir ajustando às estratégias de ensino às de aprendizagem. Daí, a importância de ele conhecer seu estilo de ensino, para articular suas práticas pedagógicas ao estilo de aprendizagem do aluno. Compreende-se neste estudo que o professor, ao conhecer seu estilo de ensino, pode alinhar de maneira mais adequada as suas estratégias para contribuir, de forma mais efetiva, com a aprendizagem do aluno, considerando seu estilo de aprender. No entanto, ele não deve buscar conhecer os estilos de aprendizagem deles exclusivamente para alinhar ao seu estilo de ensino, até mesmo porque é preciso promover o desenvolvimento de estratégias, tanto de ensino como de aprendizagem, criando situações de aprendizagem muito mais eficazes. 
Nessa perspectiva, o objetivo principal deste artigo foi evidenciar como os estilos de aprendizagem contribuem com o processo de ensino e aprendizagem na educação básica e no ensino superior. Para isso, inicialmente, apresenta-se um breve histórico e as principais características dos estilos de aprendizagem segundo Alonso, Gallego e Honey (1994). Na sequência, aborda-se a metodologia adotada para o desenvolvimento deste estudo, bem como os resultados alcançados e sua respectiva discussão. Por fim, faz-se as considerações possíveis e, lista-se as referências.

\section{Breve histórico e as principais características}

A teoria dos estilos de aprendizagem de Alonso, Gallego e Honey (1994) traz uma proposta para o professor, que vai ao encontro do que é central no processo educativo: instigar a discussão da aprendizagem, envolvendo os participantes professor e aluno - nesse processo. De acordo com estes autores, estilo de aprendizagem não deve ser confundido com estilo cognitivo, pois é importante compreender a definição clara de estilo de aprendizagem e estilo cognitivo e qual seria o mais amplo para descrever a complexidade do processamento de informação.

Portanto, para Alonso, Gallego e Honey (2007) os estilos cognitivos são "actividades intelectuales internas como la percepción, interpretación y pensamento" (p. 26). Enquanto que os estilos de aprendizagem se constituem "como los indivíduos se diferencian en el modo de iniciar, investigar, absorver, sinstetizar e evaluar las diferentes influencias educativas en su ambiente, y de integrar sus experiências, y la rapidez del Aprendizaje, etc" (p. 47). Para Hayes e Allinson (1994 apud GOMES, 2018, p. 30) os estilos cognitivos "representam as preferências individuais, o modo pelo qual uma pessoa descobre, processa e avalia os dados, que interfere na maneira como ela organiza, integra e interpreta a informação". E os estilos de aprendizagem se relacionam "com as preferências de aprendizagem, ou seja, a maneira como um conteúdo pode ser melhor aprendido. Também é considerado como um subconjunto dos estilos cognitivos, com aspectos afetivos e psicológicos" (HAYES; ALLINSON, 1994; RIDING; RAYNER, 2013 apud GOMES, 2018, p. 30).

Em Keefe (1988 apud ALONSO; GALLEGO; HONEY, 2007, p. 48), os estilos de aprendizagem "son los rasgos cognitivos, afectivos y fisiologicos, que sirven como 
indicadores relativamente estables, de cómo los discentes perciben, interaccionan y respondem a sus ambientes de Aprendizaje". Cue (2006 apud BARROS, 2009) complementa que os estilos de aprendizagem são traços cognitivos, afetivos e fisiológicos, preferencialmente utilizados pelos sentidos, segundo cada indivíduo, de acordo com seu referencial cultural, psicológico, social, que servem como indicadores relativamente estáveis de como as pessoas percebem, inter-relacionam e respondem às suas próprias estratégias de aprender. Portanto, as preferências e tendências individuais que cada aluno utiliza para aprender são classificadas, de acordo com Alonso, Gallego e Honey (2007), em quatro estilos: ativo, reflexivo, teórico e pragmático.

Para Kolb (1981 apud ALONSO; GALLEGO; HONEY, 2002) a aprendizagem ocorre por um processo cíclico, seguido de quatro etapas: experiência concreta, observação reflexiva, conceituação abstrata e experimentação ativa. Com base nesse processo, foi desenvolvido o conhecido Learning Style Inventory (L.S.I.), para identificar os estilos de aprendizagem: divergente (imagina e confronta perspectivas), assimilador (criador de modelos e raciocínio indutivo), convergente (aplicação práticas das ideias) e acomodador (executa e experimenta). Em 1990, a teoria de Kolb serve de base para Honey e Mumford desenvolverem estudos voltados à aprendizagem, para atender contextos empresariais do Reino Unido (ALONSO; GALLEGO; HONEY, 2007). Todavia, o L.S.I., desenvolvido por Kolb, não estava totalmente adequado para o objetivo pretendido por Honey e Mumford. As diferenças fundamentais, segundo Alonso, Gallego e Honey (2007, p. 69) são:

a. Las descripciones de los Estilos son más detalladas y se basan em la acción de los sujetos.

b. Las respuestas al Cuestionario son un punto de partida y no un final. Un punto de arranque, un diagnóstico seguido de un tratamiento de mejora. Se trata de facilitar una guía práctica que ayude y oriente al individuo en su mejora personal y también en la mejora de sus colegas y subordinados.

c. Describen un Cuestionario con ochenta ítems que permiten analizar una mayor cantidad de variables, que el test propuesto por Kolb.

E, finalmente, Catalina Alonso (1994) adequa o instrumento Learning Styles Questionnaire (L.S.Q.), desenvolvido por Honey e Mumford, da língua inglesa para a espanhola, acrescentando algumas perguntas socioacadêmicas e o direciona a 
estudantes universitários. Esse instrumento denominado "Cuestionário HoneyAlonso de Estilos de Aprendizaje - CHAEA", foi desenvolvido por Catalina Alonso, em 1994, vencedora do "Premio Nacional de Invstigación del Consejo de Universidades", ainda em 1991.

O "Questionario Honey-Alonso de Estilos de Aprendizagem - CHAEA", foi traduzido e adaptado por Portilho em 2003 para o português (PORTILHO, 2003). Esse instrumento contempla 80 itens, sendo 20 para cada um dos quatro estilos de aprendizagem: ativo, reflexivo, teórico e pragmático. Ao responder a cada uma das 80 questões é preciso assinalar se se está mais ou menos de acordo, sendo a maioria dos itens relacionados a comportamentos, pois visa identificar tendências gerais de comportamentos pessoais. Brognoli (2017) menciona que quando a pontuação do questionário corresponder à média entre 10 e 12 pontos para cada um dos estilos, representa que naquele momento, o aluno possui os quatros estilos e não apenas uma única tendência de estilo de aprendizagem, que se potencializado, contribui ainda mais para sua a aprendizagem.

Conforme já mencionado, o CHAEA é um instrumento que pode ser utilizado como ponto de partida pelo professor, não como um fim em si mesmo, pois oferece indicadores para a análise, frente à simples observação assistemática e contribui como apoio para ser utilizado nas interações do indivíduo com a realidade existente, passível de ser explorado ainda nos seus pormenores. Esse instrumento sintetiza os enfoques para a preferência ao aprender, tanto do professor como do aluno.

O estilo ativo aplica-se às pessoas que gostam de novas experiências, desafios, e que não gostam de grandes prazos. Gostam de se colocar no centro de todas as atividades. Pessoas com o estilo reflexivo gostam de considerar a experiência e observá-la por diferentes perspectivas. São prudentes, pois gostam de pensar em alternativas possíveis, antes de tomar uma decisão. $O$ estilo teórico aplica-se às pessoas que enfocam problemas de forma vertical, por etapas lógicas, e que tendem a ser perfeccionistas. São profundos em seu sistema de pensamento na hora de estabelecer princípios, teorias e modelos, buscam racionalidade e objetividade. O estilo pragmático cabe às pessoas que aplicam na prática as ideias, aproveitam as oportunidades para experimentá-las, e gostam de projetos que os atraem. Tomam decisões e gostam de colocá-las em prática. Partem do princípio de que sempre se 
pode fazer melhor. São práticos, diretos, rápidos, decididos, objetivos, seguros de si, organizados e solucionadores de problemas.

Pontua-se, portanto, a importância de estimular o desenvolvimento dos estilos de aprendizagem desde cedo, para que as crianças tornem-se adultas "mais aptas e dispostas a tentar e a não desistir nas diferentes situações da vida, não abandonando o seu potencial de aprendizagem. [...] aprende a lidar com as dificuldades e situações de incertezas, enfrentando os desafios que surgem no caminho” (BELTRAMI, 2008, p. 40). O professor precisa reeducar o seu olhar e ter sensibilidade para com os alunos (ARROYO, 2004). "Perceber que seu estilo de ensinar precisa ser mais flexível para atingir a solicitação do contexto onde ela está inserida, os conteúdos pertinentes daquele determinado grupo e as características dos alunos e seus conhecimentos prévios” (BELTRAMI, 2008, p. 17).

Após esse breve histórico e apresentação das principais características dos estilos de aprendizagem, menciona-se, a seguir, o percurso metodológico adotado para o desenvolvimento e sistematização deste estudo.

\section{Metodologia}

Visando alcançar o objetivo proposto, realizou-se uma pesquisa qualitativa com cunho exploratório. Esse é um tipo de pesquisa que tem o objetivo de aprimorar ideias ou "descoberta de intuições", bem como realizar um "levantamento bibliográfico" (GIL, 2002, p. 41) que "se utiliza fundamentalmente das contribuições dos diversos autores sobre determinado assunto" (GIL, 2002, p. 45). Para tanto, realizou-se um levantamento sistemático da literatura em algumas bases de dados, conforme apresentado no quadro a seguir, com o objetivo de se identificar estudos que abordam o processo de ensino e aprendizagem, na educação básica e no ensino superior, tendo como referência a teoria dos estilos de aprendizagem de Alonso, Gallego e Honey (1994). Como critério de inclusão, adotou-se: teoria de Alonso, Gallego e Honey; sem parâmetro quanto ao período de publicação; artigos e/ou anais de eventos; independentemente do qualis do periódico e/ou evento. 
Quadro 1 - Buscas realizadas

\begin{tabular}{|c|l|l|c|c|}
\hline Item & \multicolumn{1}{|c|}{ Bases de Dados } & \multicolumn{1}{|c|}{ Descritores } & Resultados & Selecionados \\
\hline 1 & $\begin{array}{l}\text { Portal de Periódicos } \\
\text { CAPES/MEC }\end{array}$ & $\begin{array}{l}\text { "estilos de aprendizagem" } \\
\text { AND “Honey-Alonso" }\end{array}$ & 9 & 2 \\
\hline 2 & $\begin{array}{l}\text { Portal de Periódicos } \\
\text { CAPES/MEC }\end{array}$ & $\begin{array}{l}\text { "learning styles" AND } \\
\text { "Honey-Alonso" }\end{array}$ & 73 & 41 \\
\hline 3 & ProQuest & $\begin{array}{l}\text { "estilos de aprendizagem" } \\
\text { AND "Honey-Alonso" }\end{array}$ & 4 & 4 \\
\hline 4 & ProQuest & $\begin{array}{l}\text { "learning styles" AND } \\
\text { "Honey-Alonso" } \\
\text { "learning styles" AND } \\
\text { "Honey-Alonso" }\end{array}$ & 19 & 2 \\
\hline 5 & SCOPUS & 34 & 51 \\
\hline \multicolumn{4}{|l}{ Total } \\
\hline
\end{tabular}

Fonte: Elaborado pelas autoras.

As buscas resultaram em 139 trabalhos. Todos os resumos foram lidos e, a partir dessa etapa, 51 artigos foram selecionados. Após a realização das leituras, na íntegra, de todos os trabalhos, destacam-se esses, que são apresentados nos quadros, a seguir:

Quadro 2 - Portal de Periódicos CAPES/MEC ("estilos de aprendizagem" AND “Honey-Alonso)

\begin{tabular}{|c|l|l|c|c|}
\hline Item & \multicolumn{1}{|c|}{ Autor / Título } & \multicolumn{1}{|c|}{ Periódico } & Ano & Qualis \\
\hline 1 & $\begin{array}{l}\text { NOGUEIRA, Daniel Ramos. Desempenho } \\
\text { acadêmico x estilos de aprendizagem segundo } \\
\text { Honey-Alonso: uma análise com alunos do curso } \\
\text { de Ciências Contábeis. }\end{array}$ & $\begin{array}{l}\text { Revista } \\
\text { Espaço } \\
\text { Acadêmico }\end{array}$ & 2012 & B5 \\
\hline 2 & $\begin{array}{l}\text { TORRES, Patricia Lupion; PORTILHO, Evelise } \\
\text { Labatut. Projeto MATICE: pretexto para a } \\
\text { discussão dos estilos de aprendizagem dos } \\
\text { professores. }\end{array}$ & $\begin{array}{l}\text { Revista } \\
\text { Diálogo } \\
\text { Educacional }\end{array}$ & 2004 & A2 \\
\hline
\end{tabular}

Fonte: Elaborado pelas autoras.

Quadro 3 - Portal de Periódicos CAPES/MEC ("learning styles” AND “Honey-Alonso)

(Continua)

\begin{tabular}{|c|l|l|c|c|}
\hline Item & \multicolumn{1}{|c|}{ Autor / Título } & \multicolumn{1}{|c|}{ Periódico } & Ano & Qualis \\
\hline 1 & $\begin{array}{l}\text { FUENTEALBA-TORRES, Miguel; NERVI } \\
\text { HALTENHOFF, Hugo. Implicaciones de los } \\
\text { estilos de aprendizaje en el uso de } \\
\text { didácticas en la práctica docente. }\end{array}$ & $\begin{array}{l}\text { Avances en } \\
\text { Enfermería }\end{array}$ & 2019 & B2 \\
\hline 2 & $\begin{array}{l}\text { JIMÉNEZ ÁLVAREZ, Leticia Salomé et al. } \\
\text { Estilos y estrategia de enseñanza- } \\
\text { aprendizaje de estudiantes universitarios de } \\
\text { la Ciencia del Suelo. }\end{array}$ & $\begin{array}{l}\text { Revista } \\
\text { Electrónica de } \\
\text { Investigación } \\
\text { Educativa }\end{array}$ & 2019 & A2 \\
\hline
\end{tabular}


Quadro 3 - Portal de Periódicos CAPES/MEC ("learning styles" AND “Honey-Alonso)

\begin{tabular}{|c|c|c|c|c|}
\hline & & & & ontinuação \\
\hline Item & Autor / Título & Periódico & Ano & Qualis \\
\hline 3 & $\begin{array}{l}\text { VALDEZ, Lilian Rossana Vera de et al. Estilos } \\
\text { de aprendizaje y rendimiento académico en } \\
\text { estudiantes de enfermería de una } \\
\text { universidad pública de Paraguay. }\end{array}$ & $\begin{array}{l}\text { NURE } \\
\text { Investigación }\end{array}$ & 2019 & B2 \\
\hline 4 & $\begin{array}{l}\text { VILLALBA, Neira Loaiza; MARTINEZ, } \\
\text { Angelmiro Galindo. Second language } \\
\text { learning styles and sequential bilingual } \\
\text { instruction in primary, secondary and } \\
\text { university education: toward a state of the } \\
\text { art. }\end{array}$ & Lenguage & 2019 & NA \\
\hline 5 & $\begin{array}{l}\text { BARRIOS-PENNA, Carolina Alejandra et al. } \\
\text { learning style variation in chilean dental } \\
\text { students from the first to fifth year. }\end{array}$ & Salud Uninorte & 2018 & NA \\
\hline 6 & $\begin{array}{l}\text { CANTÚ MARTÍNEZ, Pedro César; ROJAS } \\
\text { MÁRQUEZ, Julia Magdalena. Estilos de } \\
\text { Aprendizaje: La experiência de la Escuela } \\
\text { Preparatoria Técnica Médica em la } \\
\text { Universidad Autónoma de Nuevo León, } \\
\text { México. }\end{array}$ & $\begin{array}{l}\text { Revista } \\
\text { Electrónica } \\
\text { Educare }\end{array}$ & 2018 & B1 \\
\hline 7 & $\begin{array}{l}\text { HOYOS-FLORES, Mirko Humberto; MORI- } \\
\text { RAMIREZ, Hallder. Estilos de aprendizaje en } \\
\text { estudiantes del primer año de medicina } \\
\text { humana en la Universidad Nacional Mayor } \\
\text { de San Marcos. }\end{array}$ & $\begin{array}{l}\text { Anais de la } \\
\text { Facultad } \\
\text { Medicina }\end{array}$ & 2018 & B5 \\
\hline 8 & $\begin{array}{l}\text { ALDUCIN-OCHOA, Juan Manuel; VÁZQUEZ- } \\
\text { MARTÍNEZ, Ana Isabel. Learning styles, } \\
\text { socio-demographic variables and academic } \\
\text { performance of building engineering } \\
\text { students. }\end{array}$ & $\begin{array}{l}\text { Revista } \\
\text { Electrónica } \\
\text { Educare }\end{array}$ & 2017 & B1 \\
\hline 9 & $\begin{array}{l}\text { FREIBERG HOFFMANN, Agustín; LEDESMA, } \\
\text { Ruben; FERNANDEZ LIPORACE, Mercedes. } \\
\text { Estilos y estrategias de aprendizaje en } \\
\text { estudiantes universitarios de Buenos Aires. }\end{array}$ & $\begin{array}{l}\text { Revista de } \\
\text { Psicología }\end{array}$ & 2017 & B1 \\
\hline 10 & $\begin{array}{l}\text { FREIBERG HOFFMANN, A. et al. Estilos, } \\
\text { Estrategias y Enfoques de Aprendizaje en } \\
\text { Estudiantes Universitarios de Buenos Aires. }\end{array}$ & Psicodebate & 2017 & B4 \\
\hline 11 & $\begin{array}{l}\text { PACHECO RIOS, Rosana; MALDONADO } \\
\text { MALDONADO, Erasmo. Relación entre los } \\
\text { estilos de aprendizaje y las teorías de } \\
\text { enseñanza. }\end{array}$ & $\begin{array}{l}\text { Retos: nuevas } \\
\text { tendencias en } \\
\text { educación física, } \\
\text { deporte y } \\
\text { recreación }\end{array}$ & 2017 & B3 \\
\hline 12 & $\begin{array}{l}\text { ALDUCIN-OCHOA, Juan Manuel; VAZQUEZ- } \\
\text { MARTINEZ, Ana Isabel. Self-Assessment of } \\
\text { knowledge and academic performance } \\
\text { according to learning styles in a university } \\
\text { degree of building construction. }\end{array}$ & $\begin{array}{l}\text { Formación } \\
\text { Universtaria }\end{array}$ & 2016 & A1 \\
\hline
\end{tabular}


Quadro 3 - Portal de Periódicos CAPES/MEC ("learning styles" AND “Honey-Alonso)

\begin{tabular}{|c|c|c|c|c|}
\hline & & & & ontinuação \\
\hline Item & Autor / Título & Periódico & Ano & Qualis \\
\hline 13 & $\begin{array}{l}\text { CZEPULA, Alexandra I. et al . Predominant } \\
\text { learning styles among pharmacy students at } \\
\text { the Federal University of Paraná, Brazil. }\end{array}$ & $\begin{array}{l}\text { Pharmacy } \\
\text { Practice }\end{array}$ & 2016 & B1 \\
\hline 14 & $\begin{array}{l}\text { ESCANERO-MARCEN, Jesús F. et al. } \\
\text { Comparación de los estilos de aprendizaje } \\
\text { de los alumnos de medicina obtenidos con } \\
\text { un nuevo cuestionario con los } \\
\text { proporcionados por el cuestionario Honey- } \\
\text { Alonso (CHAEA). }\end{array}$ & $\begin{array}{l}\text { Revista de la } \\
\text { Fundación } \\
\text { Educación } \\
\text { Médica }\end{array}$ & 2016 & NA \\
\hline 15 & $\begin{array}{l}\text { HERRERA FERNÁNDEZ, Karmen Arline; } \\
\text { CAMACHO GUTIÉRREZ, Dulce Fátima; } \\
\text { HEREDIA ESCORZA, Yolanda. La relación } \\
\text { entre estilos de aprendizaje, autodirección y } \\
\text { el desempeño académico en estudiantes de } \\
\text { música de una universidad mexicana. }\end{array}$ & $\begin{array}{l}\text { Revista } \\
\text { Electrónica } \\
\text { Complutense de } \\
\text { Investigación en } \\
\text { Educación } \\
\text { Musical }\end{array}$ & 2016 & NA \\
\hline 16 & $\begin{array}{l}\text { MARTíNEZ-SANDOVAL, Gloria et al. Learning } \\
\text { styles and types of multiple intelligences in } \\
\text { dental students in their first and tenth } \\
\text { semester. }\end{array}$ & $\begin{array}{l}\text { Journal of Oral } \\
\text { Research }\end{array}$ & 2016 & B4 \\
\hline 17 & $\begin{array}{l}\text { BARRANTES, Catalina Lizano et al. Relación } \\
\text { entre estilo de Aprendizaje y rendimento } \\
\text { académico em estudiantes de farmácia de la } \\
\text { Universidade de Costa Rica. }\end{array}$ & $\begin{array}{l}\text { Revista Digital de } \\
\text { Investigación en } \\
\text { Docencia } \\
\text { Universitaria }\end{array}$ & 2015 & C \\
\hline 18 & $\begin{array}{l}\text { DOMINGUEZ RODRIGUEZ, Heriberto de } \\
\text { Jesús et al. Estilos de aprendizaje: un estudio } \\
\text { diagnóstico en el centro universitario de } \\
\text { ciencias económico-administrativas de la U } \\
\text { de G. }\end{array}$ & $\begin{array}{l}\text { Revista de la } \\
\text { Educación } \\
\text { Superior }\end{array}$ & 2015 & B1 \\
\hline 19 & $\begin{array}{l}\text { LUENGO-CERVERA, Esperanza. Learning } \\
\text { styles and multiple intelligences in the } \\
\text { teaching-learning of Spanish as a foreign } \\
\text { language. }\end{array}$ & $\begin{array}{l}\text { Enseñanza \& } \\
\text { Teaching }\end{array}$ & 2015 & NA \\
\hline 20 & $\begin{array}{l}\text { RODRIGUEZ, Paola Dolores Ordoñez. } \\
\text { Diagnóstico de la enseñanza de la } \\
\text { estadística utilizando el método del } \\
\text { aprendizaje autónomo y significativo. }\end{array}$ & $\begin{array}{l}\text { Revista Logos } \\
\text { Ciencia \& } \\
\text { Tecnología }\end{array}$ & 2015 & NA \\
\hline 21 & $\begin{array}{l}\text { ACEVEDO, Diofanor; CAVADIA, Shirley; } \\
\text { ALVIS, Armando. Learning Styles of Students } \\
\text { of the Faculty of Engineering of the } \\
\text { University of Cartagena (Colombia). }\end{array}$ & $\begin{array}{l}\text { Formación } \\
\text { Universitaria }\end{array}$ & 2015 & A1 \\
\hline 22 & $\begin{array}{l}\text { BAYONA MONTAÑO, Liliam Andrea; CAMPO } \\
\text { TORREGROSA, Yelis. Estrategias de } \\
\text { aprendizaje en relación con el rendimiento } \\
\text { académico en estudiantes de enfermeira. }\end{array}$ & Ánfora & 2014 & NA \\
\hline
\end{tabular}


Quadro 3 - Portal de Periódicos CAPES/MEC ("learning styles" AND “Honey-Alonso)

\begin{tabular}{|c|c|c|c|c|}
\hline & & & & ontinuaçãa \\
\hline Item & Autor / Título & Periódico & Ano & Qualis \\
\hline 23 & $\begin{array}{l}\text { ELVIRA-VALDES, María Antonieta; PUJOL, } \\
\text { Lydia. Cognitive Variables and University } \\
\text { Entrance: predictors of academic } \\
\text { achievement. }\end{array}$ & $\begin{array}{l}\text { Universitas } \\
\text { Psychologia }\end{array}$ & 2014 & A2 \\
\hline 24 & $\begin{array}{l}\text { BAHAMON MUNETON, Marly Johana et al. } \\
\text { Learning Styles and strategies related to } \\
\text { Academic Achievement among University } \\
\text { Students. }\end{array}$ & $\begin{array}{l}\text { Pensamiento } \\
\text { Psicológico }\end{array}$ & 2013 & B1 \\
\hline 25 & $\begin{array}{l}\text { ESCANERO-MARCEN, Jesús F. et al. Influence } \\
\text { of learning styles and metacognition in the } \\
\text { academic performance of physiology } \\
\text { students. }\end{array}$ & $\begin{array}{l}\text { Revista de la } \\
\text { Fundación } \\
\text { Educación } \\
\text { Médica }\end{array}$ & 2013 & NA \\
\hline 26 & $\begin{array}{l}\text { FREIBERG HOFFMANN, Agustín; FERNANDEZ } \\
\text { LIPORACE, Mercedes. Honey-Alonso } \\
\text { Learning Styles Questionnaire: an analysis } \\
\text { of its psychometric properties in college } \\
\text { students. }\end{array}$ & $\begin{array}{l}\text { Summa } \\
\text { Psicologica }\end{array}$ & 2013 & B1 \\
\hline 27 & $\begin{array}{l}\text { LÓPEZ, Bernardo Gargallo et al. Learning } \\
\text { styles and approaches to learning in } \\
\text { excellent and average first-year university } \\
\text { students. }\end{array}$ & $\begin{array}{l}\text { European Journal } \\
\text { of Psychology of } \\
\text { Education }\end{array}$ & 2013 & NA \\
\hline 28 & $\begin{array}{l}\text { RETANA, José Ánge Garcia. Reflections on } \\
\text { learning styles and calculus learning in } \\
\text { engineering majors. }\end{array}$ & $\begin{array}{l}\text { Actualidades } \\
\text { Investigativas en } \\
\text { Educación }\end{array}$ & 2013 & B1 \\
\hline 29 & $\begin{array}{l}\text { BAHAMON MUNETON, Marly Johana et al. } \\
\text { Estilos y estrategias de aprendizaje: una } \\
\text { revisión empírica y conceptual de los } \\
\text { últimos diez años. }\end{array}$ & $\begin{array}{l}\text { Pensamiento } \\
\text { Psicológico }\end{array}$ & 2012 & B1 \\
\hline 30 & $\begin{array}{l}\text { ALLUEVA TORRES, Pedro; BUENO GARCíA, } \\
\text { Concepción. Estilos de aprendizaje y estilos } \\
\text { de pensamiento en estudiantes } \\
\text { universitarios. Aprender a aprender y } \\
\text { aprender a pensar. }\end{array}$ & $\begin{array}{l}\text { Arbor: Ciencia, } \\
\text { Pensamiento y } \\
\text { Cultura }\end{array}$ & 2011 & NA \\
\hline 31 & $\begin{array}{l}\text { MUÑOZ, Héctor Eladio Toledo et al. } \\
\text { Evaluación de los intereses de } 7^{\circ} \text { y } 8^{\circ} \text { año de } \\
\text { enseñanza básica y } 1^{\circ} \text { y } 2^{\circ} \text { año de educación } \\
\text { media de la provincia de Llanquihue. }\end{array}$ & $\begin{array}{l}\text { Journal for } \\
\text { Educators, } \\
\text { Teachers and } \\
\text { Trainers }\end{array}$ & 2011 & NA \\
\hline 32 & $\begin{array}{l}\text { PORTILHO, Evelise Maria Labatut; MATTOS, } \\
\text { Hilda Maria Zanetti Heller de; CRUZ, Juliana } \\
\text { Boff Aramayo. O desafio de pesquisar a } \\
\text { educação infantil: limites e possibilidades. }\end{array}$ & $\begin{array}{l}\text { Revista Diálogo } \\
\text { Educacional }\end{array}$ & 2011 & A2 \\
\hline 33 & $\begin{array}{l}\text { GALDAMES, Iván Suazo et al. Professional } \\
\text { Modeling of Learning Styles does Exist? }\end{array}$ & $\begin{array}{l}\text { International } \\
\text { Journal Morphol }\end{array}$ & 2010 & B3 \\
\hline
\end{tabular}


Quadro 3 - Portal de Periódicos CAPES/MEC ("learning styles" AND “Honey-Alonso)

\begin{tabular}{|c|c|c|c|c|}
\hline & & & & (Conclusãd \\
\hline Item & Autor / Título & Periódico & Ano & Qualis \\
\hline 34 & $\begin{array}{l}\text { AGUILAR RIVERA, María del Carmen. Estilos } \\
\text { y estrategias de aprendizaje en jóvenes } \\
\text { ingresantes a la universidad. }\end{array}$ & $\begin{array}{l}\text { Revista de } \\
\text { Psicología }\end{array}$ & 2010 & B1 \\
\hline 35 & $\begin{array}{l}\text { ALARCON, Eva Villalobos. et al. Estilos de } \\
\text { aprendizaje y metodologías de enseñanza } \\
\text { en estudiantes de obstetrícia. }\end{array}$ & $\begin{array}{l}\text { Educación } \\
\text { Medica }\end{array}$ & 2009 & NA \\
\hline 36 & $\begin{array}{l}\text { ORELLANA MANRIQUE, Oswaldo et al. } \\
\text { Regimes positivos de pensamento de } \\
\text { autodialogue estilos negativos e de } \\
\text { aprendizagem em alunos university. }\end{array}$ & $\begin{array}{l}\text { Revista de } \\
\text { Investigacion en } \\
\text { Psicologia }\end{array}$ & 2009 & NA \\
\hline 37 & $\begin{array}{l}\text { BORRACCI, R. A. et al. Learning styles in } \\
\text { university students and medical residents. }\end{array}$ & $\begin{array}{l}\text { Educación } \\
\text { Médica }\end{array}$ & 2008 & NA \\
\hline 38 & $\begin{array}{l}\text { LORÍA-CASTELLANOS, Jorge et al. Learning } \\
\text { styles of resident physicians in a } 2 \text { nd. Level } \\
\text { hospital. }\end{array}$ & $\begin{array}{l}\text { Educación } \\
\text { Médica Superior }\end{array}$ & 2007 & A1 \\
\hline 39 & $\begin{array}{l}\text { CORREA BAUTISTA, Jorge Enrique. } \\
\text { Identificación de los estilos de aprendizaje } \\
\text { en los estudiantes de fisiología del ejercicio } \\
\text { de la Facultad de Rehabilitación y Desarrollo } \\
\text { Humano. }\end{array}$ & $\begin{array}{l}\text { Revista Ciencias } \\
\text { de la Salud }\end{array}$ & 2006 & B3 \\
\hline 40 & $\begin{array}{l}\text { CANALEJAS PEREZ, Matia del Coro et al. } \\
\text { Estilos de aprendizaje en los estudiantes de } \\
\text { enfermeira. }\end{array}$ & $\begin{array}{l}\text { Educación } \\
\text { Médica }\end{array}$ & 2005 & NA \\
\hline 41 & $\begin{array}{l}\text { LUENGO GONZÁLEZ, Ricardo; GONZÁLEZ } \\
\text { GÓMEZ, José Juan. Relação entre estilos de } \\
\text { aprendizagem, desempenho em } \\
\text { matemática e a escolha de disciplinas } \\
\text { eletivas em estudantes do ESO. }\end{array}$ & $\begin{array}{l}\text { Revista } \\
\text { Electrónica de } \\
\text { Pesquisa e } \\
\text { Avaliação } \\
\text { Educacional }\end{array}$ & 2005 & B2 \\
\hline & & & & \\
\hline
\end{tabular}

Fonte: Elaborado pelas autoras.

Quadro 4 - Portal de Periódicos ProQuest ("estilos de aprendizagem" AND “Honey-Alonso)

\begin{tabular}{|c|l|l|c|c|}
\hline Item & \multicolumn{1}{|c|}{ Autor / Título } & Periódico & Ano & Qualis \\
\hline 1 & $\begin{array}{l}\text { PORTILHO, Evelise et al. Brasil e Portugal. A voz } \\
\text { do professor: da narrativa à prática - um caso } \\
\text { português. }\end{array}$ & $\begin{array}{l}\text { Revista } \\
\text { Lusófona de } \\
\text { Educação }\end{array}$ & 2016 & A1 \\
\hline
\end{tabular}

Fonte: Elaborado pelas autoras. 
Quadro 5 - Portal de Periódicos ProQuest ("learning styles" AND “Honey-Alonso)

\begin{tabular}{|c|l|l|c|c|}
\hline Item & \multicolumn{1}{|c|}{ Autor / Título } & \multicolumn{1}{|c|}{ Periódico } & Ano & Qualis \\
\hline 1 & $\begin{array}{l}\text { BARRIOS-PENNA, Carolina Alejandra et al. } \\
\text { learning style variation in chilean dental } \\
\text { students from the first to fifth year. }\end{array}$ & Salud Uninorte & 2018 & NA \\
\hline 2 & $\begin{array}{l}\text { CARRASCAL, Ana Isabel Oviedo; JIMÉNEZ, } \\
\text { Gabriel Almendrales. Estudio sobre Estilos } \\
\text { de Aprendizaje mediante Minería de Datos } \\
\text { como apoyo a la Gestión Académica en } \\
\text { Instituciones Educativas. }\end{array}$ & $\begin{array}{l}\text { Revista Ibérica } \\
\text { de Sistemas e } \\
\text { Tecnologias de } \\
\text { Informação }\end{array}$ & 2018 & B4 \\
\hline 3 & $\begin{array}{l}\text { MARTínEZ, Nicolás Ros. Influencia de la } \\
\text { inteligencia emocional en los estilos de } \\
\text { aprendizaje predominantes de los alumnos } \\
\text { de bachillerato de la modalidad de Artes. }\end{array}$ & $\begin{array}{l}\text { Educatio Siglo } \\
\text { XXI }\end{array}$ & 2015 & C \\
\hline 4 & $\begin{array}{l}\text { VÁZQUEZ, Maria de Jesús Araiza; DÖRFER, } \\
\text { Claudia; CORPUS, Rosalinda Castillo. } \\
\text { Academic Progress Depending on the Skills } \\
\text { and Qualities of Learning in Students of a } \\
\text { Business School. }\end{array}$ & $\begin{array}{l}\text { Turkish Online } \\
\text { Journal of } \\
\text { Educational } \\
\text { Technology - } \\
\text { TOJET }\end{array}$ & 2015 & B5 \\
\hline
\end{tabular}

Fonte: Elaborado pelas autoras.

Quadro 6 - Portal de Periódicos SCOPUS ("learning styles” AND “Honey-Alonso)

\begin{tabular}{|c|l|c|c|c|}
\hline Item & \multicolumn{1}{|c|}{ Autor / Título } & Periódico & Ano & Qualis \\
\hline 1 & $\begin{array}{l}\text { FERNANDES, Susana C. F.; SIMOES, Ricardo. } \\
\text { Collaborative use of different learning styles } \\
\text { through 3D printing. }\end{array}$ & Anais & 2016 & NA \\
\hline 2 & $\begin{array}{l}\text { GONZALEZ, Fidelina; SÁEZ, Katia; RAMÍREZ, Julia. } \\
\text { Learning style profiles and academic } \\
\text { improvement in the first year of nursing. }\end{array}$ & $\begin{array}{l}\text { Ciencia y } \\
\text { enfermería }\end{array}$ & 2016 & B1 \\
\hline
\end{tabular}

Fonte: Elaborado pelas autoras.

As contribuições desses pesquisadores, a respeito dos estilos de aprendizagem, são discutidas no item "Resultados e Discussões", a seguir:

\section{Resultados e discussões}

Nogueira (2012) reporta que as Instituições de Ensino Superior (IES) nos últimos anos têm demonstrado grande preocupação com o desempenho dos alunos nas avaliações internas, assim como nas avaliações promovidas por agências 
reguladoras, "uma vez que pode-se por meio destas notas entender em qual nível a IES está em relação às demais, além é claro, da preocupação de demonstrar bons indicadores [...]." (p. 81), segundo os parâmetros estabelecidos. Compreende-se, portanto, que existe a interferência direta das determinações do mercado de capital, na elaboração dos currículos, consequentemente, servindo de parâmetros para as avaliações governamentais.

Sendo assim, tais currículos são estabelecidos, e para isso, exige-se o desenvolvimento de determinados conteúdos, que são avaliados conforme os indicadores estipulados. Se o resultado desse processo não atinge os parâmetros propostos, compreende-se que o processo de ensino e aprendizagem é falho. Por isso, Bayona Montaño e Campo Torregosa (2014) alertam sobre a importância da questão da didática do professor, sendo esse o elemento-chave para ensinar, de modo que se proporcione ao aluno ter o melhor "rendimento" acadêmico. Esse desempenho do aluno é afetado por questões emocionais, psicológicos, sociais, familiares, motivação e expectativas, impactando na aprendizagem.

Nesse sentido, Freiberg Hoffmann e Fernandez Liporace (2013); Freiberg Hoffmann; Ledesma, Fernandez Liporace (2017); Carrascal e Jiménez (2018), complementam, indicando outros fatores, que também afetam a aprendizagem, tais como: questões sócio-demográficas e características acadêmicas (falta, participação em aula, rendimento acadêmico no ensino médio), dentre outros determinantes não discutidos neste artigo.

Diante dessas causas, Cantú Martínez e Rojas Márquez (2018) e LoríaCastellanos et al. (2007) elencam alguns aspectos que podem estar relacionados também com a aprendizagem, como: as formas de processar e perceber a informação não se dão do mesmo modo em todos os alunos; é preciso considerar o que o aluno já sabe; pois se percebe que a disciplina é pensada considerando um tipo de aluno ideal. Portanto, se tais questões não forem consideradas no planejamento e desenvolvimento do processo de aprendizagem no que tange às ações pedagógicas e suas articulações, considerando o aluno real, o melhor desempenho acadêmico pode não acontecer.

Pacheco Rios e Maldonado Maldonado (2017) complementam, salientando que as disciplinas são pensadas para um tipo ideal de aluno. E por esse motivo é que 
deve-se desenvolver nos alunos todos os estilos de aprendizagem, assim como o professor necessita utilizar-se de várias estratégias de ensino, evitando o que Alarcon (2009) pontua a respeito de os alunos se adaptarem ao estilo de ensino do professor, e por fim, preferirem, por exemplo, apenas a metodologia de aula expositiva.

Por isso, é fundamental conhecer quem é esse aluno, suas preferências para aprender de uma maneira e não de outra, visto que as estratégias de ensino mais adequadas, quando utilizadas pelos professores, podem reforçar os estilos de preferência e potencializar outros estilos de aprendizagem menos desenvolvidos (ALONSO; GALLEGO; HONEY, 2007). No entanto, quando isso não ocorre, "podem estar se desenvolvendo contrariamente ao processo natural de aprendizagem" (CORREA BAUTISTA, 2006, p. 9). "El rendimento académico de um estudiante está determinado por múltiples variables, siendo uma de ellas el estilo de Aprendizaje. Esta variable pueder ayudar o dificultar el processo, dependendo de las demandas de cada curso" (BARRANTES et al., 2015, p. 60).

Alonso, Gallego e Honey (2007) pontuam que as características dos cursos superiores influenciam o estilo de aprendizagem, principalmente se os conteúdos foram pensados para atender um tipo específico de aluno, o "ideal", conforme determina e requer as agências reguladoras. Isso posto, Aguilar Rivera (2010); Alducin-Ochoa e Vasquez-Martínez (2016); Galdames et al. (2010) menciona que é necessário utilizar estratégias de ensino que facilitem a aprendizagem dos conteúdos, sendo elas, portanto, utilizadas para atender, muitas vezes, apenas a questão da formação profissional.

Nesse sentido, Alducin-Ochoa e Vasquez-Martínez (2017) sinalizam que os profissionais de engenharia, para atuar efetivamente no exercício da profissão, terão melhores desempenhos a partir dos quatro estilos de aprendizagem desenvolvidos. No entanto, para Bahamón Muñetón et al. (2012) não somente a área de engenharia, mas o importante é que para facilitar o enfrentamento de todas as situações do cotidiano, o aluno possa ter desenvolvido os quatros estilos de aprendizagem.

Luengo González e González Gómez (2005) reforçam que o sistema educacional não é neutro, pois desenvolve os conteúdos por meio das disciplinas, tendo como base conteúdos que são determinados para atender o estilo de aprendizagem teórico e reflexivo. Corrobora Valdez (2019) sinaliza que os modelos 
pedagógicos elaborados para a educação superior seguem essa mesma lógica. De acordo com os estudos de Portilho, Mattos e Cruz (2011), após aplicação do CHAEA, o resultado indicou que as professoras da educação infantil consideravamse reflexivas. No entanto, entre as sete professoras participantes, "apenas duas, as mesmas que apresentaram nos relatos indícios de pesquisadoras, revelaram no seu discurso características desse estilo” (p. 137). Sendo assim, não há evidências desse estilo sendo reproduzidas nas ações pedagógicas e metodológicas. Todavia, "a partir dessa constatação, pergunta-se: será que as professoras apresentam estilo de aprendizagem reflexivo ou gostariam de ter esse estilo por ser o mais valorizado pela cultura contemporânea?” (p. 139).

Luengo-Cervera (2015) e Martínez-Sandoval et al. (2016) mencionam em seus estudos que os estilos reflexivos são aqueles que apresentam alto rendimento acadêmico. Ocorre que o aluno que tem preferência por aprender considerando outros estilos, consequentemente, terá dificuldades de aprendizagem.

De acordo com os estudos de Acevedo, Cavadia e Alvis (2015); AlducinOchoa e Vasquez-Martínez (2016); Alarcon (2009); Bayona Montaño e Campo Torregosa (2014); Escanero-Marcén et al. (2013); Luengo-Cervera (2015); Luengo González e González Gómez (2005); López et al. (2013); Martínez-Sandoval et al. (2016); Nogueira (2012); Valdez et al. (2019), a maioria dos alunos possui o estilo de aprendizagem reflexivo. O mesmo ocorre com os estilos dos professores. Torres e Portilho (2004) relatam que o estilo reflexivo é o que predomina também entre os professores, tanto que parece fazer parte da cultura brasileira.

Retana (2013, p. 2) aborda que a aprendizagem é influenciada pelas características cognitivas das disciplinas, por exemplo, Matemática "dificulta cuando las matemáticas se enseñan en calidad de conceptos abstractos y etéreos, descontextualizados, caracterizados por constituir una colección de fórmulas algebraicas, cuya única razón de ser es ser ellas mismas". Daí, é preciso considerar, por exemplo, que a fórmula para o cálculo na Matemática é uma ferramenta que existe para auxiliar nas resoluções de problemas do cotidiano e não deve ser pensada como produto. Freiberg Hoffmann et al. (2017) mencionam que a apropriação do estilo de aprendizagem pelo aluno facilita o desenvolvimento dos processos cognitivos requeridos pela disciplina. Portanto, é essencial, segundo Hoyos-Flores, Mori-Ramirez (2018) e Jiménez Álvarez et al. 
(2019), identificar os estilos de aprendizagem dos alunos, bem como estimular o desenvolvimento de outros estilos, visando contribuir com o seu aprendizado nas diferentes áreas do conhecimento.

Todavia, tal discurso conduz ao pensamento de que numa aprendizagem articulada à adaptação, considera-se um currículo voltado apenas à formação profissional. Contrariamente, o conteúdo curricular não deve ser compreendido apenas para atender a formação profissional e tampouco, como produto em si mesmo. Deve-se vislumbrar os estilos de aprendizagem como elemento que contribui e impacta significativamente na aprendizagem. Pressupõe-se que é fundamental compreender quais são os conhecimentos que o aluno já possui e sabe articular, para que se possa criar situações favoráveis para a construção de novos conhecimentos. Por isso, é importante o que menciona Muñoz et al. (2011, p. 46): "la contextualización no se ve inserta en el tratamiento de los contenidos", devendo estar inserida e ser estratégica na articulação com o conteúdo a ser trabalho e abordado, "lo que permitiría posteriormente mayores niveles de conexiones de aprendizajes".

Por isso, Fuentealba-Torres e Nervi Haltenhoff (2019); González, Sáez e Ramírez (2016) alertam que ao identificar o estilo de aprendizagem preferido do aluno, facilita ao professor, desenvolver estratégias de ensino mais eficazes, favorecendo a criação de um clima mais acolhedor, promovendo a participação do aluno. Aquela mais efetiva, como protagonista no processo de aprendizagem pode impactar num melhor desempenho acadêmico (GONZÁLEZ; SÁEZ; RAMÍREZ, 2016; MARTÍNEZ, 2015).

Esse clima acolhedor, que ocorre no exercício permanente do educador com os saberes, é relatado por Freire (2015, p. 12) como sendo "a convivência amorosa com seus alunos e na postura curiosa e aberta que assume e, ao mesmo tempo, provoca-os a se assumirem enquanto sujeitos sócio-histórico-culturais do ato de conhecer, é que ele pode falar do respeito à dignidade e autonomia do educando". Corroboram Dominguez Rodriguez (2015), Fernandes e Simões (2016) que tal situação instiga o aluno a buscar informações ainda não vistas, favorecendo a aprendizagem autônoma, ativa e significativa, inter-relacionada com a realidade existente (CORREA BAUTISTA, 2006; RODRIGUEZ, 2015), que "pressupõe 
romper com concepções e práticas que negam a compreensão da educação como uma situação gnosológica” (FREIRE, 2015, p. 12).

Nesse contexto, ao professor cabe conhecer a preferência pelo modo de aprender do aluno, pois vai "ficando cada vez mais claro que, embora diferentes entre si, quem forma se forma e re-forma ao formar e quem é formado forma-se e forma ao ser formado" (FREIRE, 2015, p. 25). Com isso, emerge a dinâmica da relação humana "quem ensina aprende ao ensinar e quem aprende ensina ao aprender” (Ibid). Portanto, Allueva Torres e Bueno García (2011) e Bahamón Muñetón et al. (2013) evidenciam que o professor deve levar o aluno a aprender a pensar, assim como a ter consciência de que o seu estilo de ensinar deve convergir para o estilo de aprender (PORTILHO et al., 2016).

Segundo Alonso, Gallego e Honey (2007) o sucesso acadêmico do aluno é influenciado pelo seu estilo de aprendizagem, o que pode ser evidenciado nos estudos de Canalejaz Pérez et al. (2005); Czepula et al. (2016); Dominguez Rodriguez (2015); Freiberg Hoffmann, Ledesma e Fernandez Liporace (2017); López et al. (2013). Este último menciona que quando as atividades pedagógicas são articuladas às estratégias de ensino, caminha-se ao encontro das preferências dos alunos que atingem melhores e muitas vezes altos níveis de desempenho acadêmico. López et al. (2013) pontuam ainda que o processo de ensino e aprendizagem, mediado por professores e os demais colegas é essencial, pois se aprende melhor o que é descoberto e construído por nós mesmos com a ajuda de outras pessoas, do que quando se recebe algo que já foi preparado por alguém que restringe as ações a um ato mecânico de memorização.

Ao atingir os níveis mais altos de aprendizagem, há um desenvolvimento de todos os estilos de aprendizagem, o que significa que os alunos articulam a aprendizagem por meio de diferentes estratégias e têm capacidade de mobilizar as informações, suscitando assim novas perguntas para as respostas conhecidas, demonstrando-se capaz de lidar com diferentes situações, enfrentando-as, o que facilita o aprendizado (BARRIOS-PENNA et al., 2018).

Borracci et al. (2008) observa em seus estudos que parece não haver relação entre os estilos de aprendizagem e o rendimento acadêmico. Infere-se assim, ao que mencionam Herrera Fernández; Camacho Gutiérrez, Heredia Escorza (2016) e 
Escanero-Marcen et al. (2013), que o desempenho acadêmico tem relação com a auto-regulação. Contudo, Escanero-Marcen et al. (2016) reporta que os estilos de ensino e estilos de aprendizagem, devem ser analisados considerando as particularidades que residem em cada contexto escolar, o currículo, as disciplinas, a didática e o conteúdo.

Alonso, Gallego e Honey (2007) mencionam que a idade e sexo influenciam em seus estilos de aprendizagem, aspecto que não é confirmado nos estudos de Acevedo, Cavadia e Alvis (2015); Alducin-Ochoa e Vasquez-Martínez (2016); Barrantes et al. (2015); Orellana Manrique (2009). Contudo, Villalba e Martinez (2014) pontuam que à medida que o aluno amadurece cognitivamente, ocorre um progresso significativo e acaba, de acordo com Vázquez, Dörfer e Corpus (2015), buscando estratégias de aprendizagem, como: aquisição, codificação, recuperação e suporte.

Elvira-Valdes e Pujol (2014) sugerem que pesquisas a respeito dos estilos de aprendizagem que articulam autorregulação; modalidades de ingresso e desempenho acadêmico sejam desenvolvidas, principalmente no ensino médio, visto que raras são as pesquisas voltadas a esse nível de ensino. Dos 51 trabalhos selecionados para o desenvolvimento desta investigação, apenas os de Luengo González e González Gómez (2005); Muñoz et al. (2011); Villalba e Martínez (2019) investigam o contexto do ensino médio. Abordam os anos iniciais e finais do ensino fundamental, os trabalhos de Portilho et al. (2016); Portilho, Mattos e Cruz (2011); Torres e Portilho (2004), os demais trabalhos enfocam, especificamente, o ensino superior.

Uma vez apresentados os resultados e as devidas discussões, algumas considerações são possíveis de serem compartilhadas.

\section{Considerações possíveis}

A partir do objetivo proposto, foi possível evidenciar como os estilos de aprendizagem contribuem com o processo de ensino e de aprendizagem, na educação básica e no ensino superior. Os conteúdos curriculares apresentam-se articulados aos parâmetros e determinações de agências reguladoras, em qualquer nível de ensino. Sendo assim, estes possuem características cognitivas próprias, que 
não atendem às preferências pelo processo de aprender de todos os alunos, ou seja, não atendem aos quatros estilos de aprendizagem. Daí a questão de os estilos de aprendizagem serem desenvolvidos pelos alunos de acordo com a orientação do professor, o que facilita aprender de diferentes formas, uma vez que as características dos estilos estarão presentes em intensidades diferentes, considerando as diferenças nas situações de aprendizagem.

Portanto, os estilos de aprendizagem também contribuem com o desenvolvimento de novos aprendizados, quando as estratégias de ensino propostas pelos professores convergem para as preferências por aprender, conhecidas e desenvolvidas pelos próprios alunos.

Nesse sentido, os estilos de aprendizagem podem ser compreendidos como um ponto de partida que auxilia no desencadeamento do complexo processo de construção de novos conhecimentos. Entende-se que reconhecer tais estilos contribui para a minimização das lacunas existentes no processo de ensino e aprendizagem. Por essa razão, torna-se importante no contexto escolar, pois favorece o ir além da preparação profissional, voltada às exigências impostas pelo mercado de trabalho.

\section{Referências}

ACEVEDO, D.; CAVADIA, S.; ALVIS, A. Learning Styles of Students of the Faculty of Engineering of the University of Cartagena (Colombia). Formación Universitaria, La Serena, v. 8, n. 4, p. 15-22, 2015. Doi: http://dx.doi.org/10.4067/S0718-50062015000400003. Acesso em: 18 out. 2019.

AGUILAR RIVERA, M. del C. Estilos y estrategias de aprendizaje en jóvenes ingresantes a la universidad. Revista de Psicología, v. 28, n. 2, p. 208-226, 2010. Disponível em: $<$ http://revistas.pucp.edu.pe/index.php/psicologia/article/view/1460>. Acesso em: 18 out. 2019.

ALARCON, E. V. et al. Estilos de aprendizaje y metodologías de enseñanza en estudiantes de obstetricia. Educación Medica, v. 12, n. 1, p. 43-46, mar. 2009. Disponível em: $<$ http://scielo.isciii.es/scielo.php?script=sci_arttext\&pid=S1575-18132009000100007\&lng=es\&nrm=iso $>$. Acesso em: 18 out. 2019.

ALDUCIN-OCHOA, J. M.; VAZQUEZ-MARTINEZ, A. I. Self-Assessment of knowledge and academic performance according to learning styles in a university degree of building construction. Formación Universtaria, La Serena, v. 9, n. 2, p. 29-40, 2016. doi http://dx.doi.org/10.4067/S0718-50062016000200004. 
ALDUCIN-OCHOA, J. M.; VÁZQUEZ-MARTÍNEZ, A. I. Learning styles, sociodemographic variables and academic performance of building engineering students. Revista Electrónica Educare, v. 21, n. 1, p. 1-31, jan. 2017. doi https://doi.org/10.15359/ree.21-1.18. Acesso em: 18 out. 2019.

ALLUEVA TORRES, P.; BUENO GARCÍA, C. Estilos de aprendizaje y estilos de pensamiento en estudiantes universitarios. Aprender a aprender y aprender a pensar. Arbor: Ciencia, Pensamiento y Cultura, v. 187, extra 3, p. 261-266, dez. 2011. doi 10.3989/arbor.2011.Extra-3n3155. Acesso em: 18 out. 2019.

ALONSO, C. M.; GALLEGO, D. J.; HONEY, P. Los estilos de aprendiraje: procedimentos de diagnostic e meyora. Bilbao, Espanha: Ediciones Mensajero, 1994.

ALONSO, C. M.; GALLEGO, D. J.; HONEY, P. Los estilos de aprendizaje: procedimentos de diagnostic e meyora. Bilbau, Espanha: Ediciones mensajero, 2007.

ALONSO, C. M.; GALLEGO, D. J.; HONEY, P. Aprendizaje y ordenador. Madrid: Dykinson, 2002.

ARROYO, M. G. Imagens quebradas: trajetórias e tempos de alunos e mestres. Petrópolis: Vozes, 2004.

BACHELARD, G. Epistemologia. Barcelona: Anagrama, 1989.

BACHELARD, G. A formação do espirito científico. Rio de Janeiro: Contraponto, 1996.

BAHAMÓN MUNETÓN, M. J. et al. Estilos y estrategias de aprendizaje: una revisión empírica y conceptual de los últimos diez años. Pensamiento Psicológico, Cali, v. 10, n. 1, p. 129-144, jun. 2012. Disponível em: <http://www.scielo.org.co/scielo.php?script=sci_arttext\&pid=S165789612012000100009\&lng=en\&nm=iso>. Acesso em: 18 out. 2019.

BAHAMÓN MUÑETÓN, M. J. et al. Learning Styles and strategies related to Academic Achievement among University Students. Pensamiento Psicológico, Cali, v. 11, n. 1, p. 115-129, jun. 2013. Disponível em: <http://www.scielo.org.co/scielo.php?script=sci_arttext\&pid=S165789612013000100008\&lng=en\&nrm=iso >. Acesso em: 18 out. 2019.

BARRIOS-PENNA, C. A. et al. learning style variation in chilean dental students from the first to fifth year. Salud Uninorte, Barranquilla, v. 34, n. 2, p. 323-337, 2018. Disponível em: $<$ https://search.proquest.com/docview/2203250872?accountid=43603>. Acesso em: 18 out. 2019.

BARRANTES, C. L. et al. Relación entre estilo de Aprendizaje y rendimento académico em estudiantes de farmácia de la Universidade de Costa Rica. Revista Digital de Investigación en Docencia Universitaria (RIDU), Lima, Perú, n. 2, 2015. doi https://doi.org/10.19083/ridu.9.434.

BARROS, D. M. V. Estilos de uso do espaço virtual: como se aprende e se ensina no virtual? Inter-Ação: revista da Faculdade de Educação da Universidade Federal de Goiás, v. 34, n. 1.2009.

BAYONA MONTAÑO, L. A.; CAMPO TORREGROSA, Y. Estrategias de aprendizaje en relación con el rendimiento académico en estudiantes de enfermería. Ánfora, Universidad Autónoma de Manizales, v. 21, n. 36, p. 149-163, 2014. Disponível em: $<$ https://publicaciones.autonoma.edu.co/index.php/anfora/article/view/39/34>. Acesso em: 18 out. 2019. 
BECKER, P. Caracterização dos estilos e estratégias de aprendizagem dos estudantes do curso de farmácia da UFS. 2013. 116 f. Dissertação (Mestrado em Ciências da Saúde) — Universidade Federal de Sergipe, Aracaju, 2013. Disponível em: < https://ri.ufs.br/handle/riufs/3674>. Acesso em: 20 maio 2019.

BELTRAMI, K. Inventário de estilo de aprendizagem para criancas Portilho/Beltrami: o estilo de aprendizagem das crianças e da professora da educação infantil. 2008. 148 f. Dissertação (Mestrado em Educação) - Pontifícia Universidade Católica de Curitiba, Curitiba, 2008. Disponível em: <http://www.bibliotecapucpr.br/tede/tde_busca/arquivo.php?codArquivo=1161>. Acesso em: 20 ago. 2019.

BORRACCI, R. A. et al. Learning styles in university students and medical residents. Educación Médica, v. 11, n. 4, p. 229-238, dez. 2008. Disponível em: $<$ http://scielo.isciii.es/scielo.php?script=sci_arttext\&pid=S1575-18132008000400007\&lng=en\&nrm=iso $>$. Acesso em: 18 out. 2019.

BROGNOLI, S. M. M. Os estilos de aprendizagem e os estilos de ensino de professores do Curso de Direito de um Centro Universitário do estado de Santa Catarina. 2017. 132 f. Dissertação (Mestrado em Educação) - Pontifícia Universidade Católica de Curitiba, Curitiba, 2017. Disponível em: <https://sucupira.capes.gov.br/sucupira/public/consultas/coleta/trabalho Conclusao $/$ view TrabalhoConclusao.jsf?popup $=$ true\&id_trabalho $=5531220>$. Acesso em: 20 ago. 2019.

CANALEJAS PEREZ, M. del C. et al. Estilos de aprendizaje en los estudiantes de enfermería. Educación Médica, v. 8, n. 2, p. 33-40, jun. 2005. Disponível em: $<$ http://scielo.isciii.es/scielo.php?script=sci_arttext\&pid=S1575-18132005000200006\&lng=en\&nmm=iso $>$. Acesso em: 18 out. 2019.

CANTÚ MARTÍNEZ, P. C.; ROJAS MÁRQUEZ, J. M. Estilos de Aprendizaje: La experiência de la Escuela Preparatoria Técnica Médica em la Universidad Autónoma de Nuevo León, México. Revista Electrónica Educare, Costa Rica, v. 22, n. 2, p. 1-8, maio/ago. 2018. doi http://dx.doi.org/10.15359/ree.22-2.3. Acesso em: 18 out. 2019.

CARRASCAL, A. I. O.; JIMÉNEZ, G. A. Estudio sobre Estilos de Aprendizaje mediante Minería de Datos como apoyo a la Gestión Académica en Instituciones Educativas. Revista Ibérica de Sistemas e Tecnologias de Informação, Lousada, n. 29, p. 1-13, 2018. doi 10.170i3/risti.29.1-13. Acesso em: 18 out. 2019.

CORREA BAUTISTA, J. E. Identificación de los estilos de aprendizaje en los estudiantes de fisiología del ejercicio de la Facultad de Rehabilitación y Desarrollo Humano. Revista Ciencias de la Salud, Bogotá, v. 4, n. 2, p. 41-53, dez. 2006. Disponível em: $<$ http://www.scielo.org.co/scielo.php?script=sci_arttext\&pid=S1692-72732006000200006\&lng=en\&nmm=iso>. Acesso em: 18 out. 2019.

CZEPULA, A. I. et al. Predominant learning styles among pharmacy students at the Federal University of Paraná, Brazil. Pharmacy Practice (Granada), Redondela, v. 14, n. 1, mar. 2016. doi: http://dx.doi.org/10.18549/PharmPract.2016.01.650. Acesso em: 18 out. 2019.

DOMINGUEZ RODRIGUEZ, H. de J. et al. Estilos de aprendizaje: un estudio diagnóstico en el centro universitario de ciencias económico-administrativas de la U de G. Revista de la Educación Superior, México, v. 44, n. 175, p. 121-140, set. 2015. Disponível em: $<$ http://www.scielo.org.mx/scielo.php?script=sci_arttext\&pid=S0185-27602015000300006\&lng $=$ en\&nmm=iso $>$. Acesso em: 18 out. 2019. 
ELVIRA-VALDES, M. A.; PUJOL, L. Cognitive Variables and University Entrance: predictors of academic achievement. Universitas Psychologia, Bogotá, v. 13, n. 4, p. 1557-1567, dez. 2014. doi http://dx.doi.org/10.11144/Javeriana.UPSY13-4.vciu. Acesso em: 18 out. 2019.

ESCANERO-MARCEN, J. F. et al. Comparación de los estilos de aprendizaje de los alumnos de medicina obtenidos con un nuevo cuestionario con los proporcionados por el cuestionario Honey-Alonso (CHAEA). Revista de la Fundación Educación Médica (FEM), Barcelona, v. 19, n. 1, p. 19-26, fev. 2016. Disponível em: $<$ http://scielo.isciii.es/scielo.php?script=sci_arttext\&pid=S2014-98322016000100006\&lng=en\&nrm=iso $>$. Acesso em: 18 out. 2019.

ESCANERO-MARCEN, J. F. et al. Influence of learning styles and metacognition in the academic performance of physiology students. Revista de la Fundación Educación Médica (FEM), Barcelona , v. 16, n. 1, p. 23-29, mar. 2013. doi http://dx.doi.org/10.4321/S2014-98322013000100005. Acesso em: 18 out. 2019.

FERNANDES, S. C. F.; SIMOES, R. Collaborative use of different learning styles through $3 \mathrm{D}$ printing. In: $2^{\text {nd }}$ International Conference of the Portuguese Society for Engineering Education (CISPEE), 2016, Vila Real, Portugal. Anais [...]. Vila Real, Portugal, 2016. p. 1-8. doi 10.1109/CISPEE.2016.7777742. Acesso em: 18 out. 2019.

FERREIRA, L. de F. Estratégias de aprendizagem do aluno de $5^{a}$ série na resolução de situaçãoproblema. 2007. 125 f. Dissertação (Mestrado em Educação) - Pontifícia Universidade Católica do Paraná, Curitiba, 2007. Disponível em: $<$ http://www.biblioteca.pucpr.br/tede/tde_busca/arquivo.php?codArquivo=1096>.

Acesso em: 20 maio 2019.

FREIRE, P. Pedagogia da autonomia: saberes necessários à prática educativa. 52. ed. Rio de Janeiro: Paz e Terra, 2015.

FREIBERG HOFFMANN, A.; FERNANDEZ LIPORACE, M. Honey-Alonso Learning Styles Questionnaire: an analysis of its psychometric properties in college students. Summa Psicologica, UST, v. 10, n. 1, p. 103-117, jul. 2013. Doi https://doi.org/10.18774/448x.2013.10.41. Acesso em: 18 out. 2019.

FREIBERG HOFFMANN, A.; LEDESMA, R.; FERNANDEZ LIPORACE, M. Estilos y estrategias de aprendizaje en estudiantes universitarios de Buenos Aires. Revista de Psicología, Lima, v. 35, n. 2, p. 535-573, 2017. Disponível em: $<$ http://www.scielo.org.pe/scielo.php?script=sci_arttext\&pid=S0254-

92472017000200005\&lng=es\&nrm=iso >. Acesso em: 18 out. 2019.

FREIBERG HOFFMANN, A. et al. Estilos, Estrategias y Enfoques de Aprendizaje en Estudiantes Universitarios de Buenos Aires. Psicodebate, v. 17, n. 1, p. 9-34, 2017. doi: https://doi.org/10.18682/pd.v17i1.626. Acesso em: 18 out. 2019.

FUENTEALBA-TORRES, M.; NERVI HALTENHOFF, H. Implicaciones de los estilos de aprendizaje en el uso de didácticas en la práctica docente. Avances en Enfermería, Bogotá, v. 37, n. 2, p. 189-197, ago. 2019. doi: http://dx.doi.org/10.15446/av.enferm.v37n2.75179. Acesso em: 18 out.2019. 
GALDAMES, I. S. et al. Existe Modelamiento Profesional de los Estilos de Aprendizaje? International Journal Morphol, Temuco, v. 28, n. 1, p. 13-18, mar. 2010. doi: http://dx.doi.org/10.4067/S0717-95022010000100002. Acesso em: 18 out. 2019.

GAMBOA, S. S. Saberes, conhecimentos e as pedagogias das perguntas e das respostas: atualidade de antigos conflitos. Práxis Educativa, Ponta Grossa, v. 4, n. 1, p. 9-19, jan./jun. 2009. Disponível em: <https://www.revistas2.uepg.br/index.php/praxiseducativa/article/view/466/467>. Acesso em: 20 jan. 2020.

GIL, A. C. Como elaborar projetos de pesquisa. 4. ed. São Paulo: Atlas, 2002.

GOMES, F. D. Ferramentas de gestão do conbecimento e estilos de aprendizagem para apoio às estratégias pedagógicas no ensino superior. 2018. 148 f. Tese (Doutorado Sistemas de Informação e Comunicação) - Universidade Estadual de Campinas, Campinas, 2018. Disponível em: https://sucupira.capes.gov.br/sucupira/public/consultas/coleta/trabalhoConclusao/view TrabalhoConclusao.jsf?popup=true\&id_trabalho=7651412. Acesso em: 20 ago. 2019.

GONZALEZ, F.; SÁEZ, K.; RAMÍREZ, J. Learning style profiles and academic improvement in the first year of nursing. Ciencia y enfermería, Concepción,Chile, v. 22, n. 1, p. 87-99, abr. 2016. doi http://dx.doi.org/10.4067/S0717-95532016000100008. Acesso em: 18 out. 2019.

HERRERA FERNÁNDEZ, K. A.; CAMACHO GUTIÉRREZ, D. F.; HEREDIA ESCORZA, Y. La relación entre estilos de aprendizaje, autodirección y el desempeño académico en estudiantes de música de una universidad mexicana. Revista Electrónica Complutense de Investigación en Educación Musical (RECIEM), v. 13, p. 1-21, 2016. doi https://doi.org/10.5209/RECIEM.51493. Acesso em: 18 out. 2019.

HOYOS-FLORES, M. H.; MORI-RAMIREZ, H. Estilos de aprendizaje en estudiantes del primer año de medicina humana en la Universidad Nacional Mayor de San Marcos. Anais de la Facultad Medicina, Lima, v. 79, n. 4, p. 367-368, out. 2018. doi http://dx.doi.org/10.15381/anales.v79i4.15645. Acesso em: 18 out. 2019.

ILLERIS, K. Uma compreensão abrangente sobre a aprendizagem humana. In: ILLERIS, K. Teorias contemporâneas da aprendizagem. Trad. Ronaldo Cataldo Costa. Porto Alegre: Penso, 2013. p. 15-30.

JIMÉNEZ ÁLVAREZ, L. S. et al. Estilos y estrategia de enseñanza-aprendizaje de estudiantes universitarios de la Ciencia del Suelo. Revista Electrónica de Investigación Educativa, v. 21, n. 4, p. 1-10, 2019. doi http://dx.doi.org/10.24320/redie.2019.21.e04.1935. Acesso em: 18 out. 2019.

LÓPEZ, B. G. et al. Learning styles and approaches to learning in excellent and average first-year university students. European Journal of Psychology of Education, n. 28, v. 4, dez. 2013. doi: 10.1007/s10212-012-0170-1.

LORÍA-CASTELLANOS, J. et al. Learning styles of resident physicians in a $2^{\text {nd }}$. Level hospital. Educación Médica Superior, Habana, v. 21, n. 3, set. 2007. Disponível em: $<$ http://scielo.sld.cu/scielo.php?script=sci_arttext\&pid=S086421412007000300001\&lng=en\&nrm=iso $>$. Acesso em: 18 out. 2019. 
LUENGO-CERVERA, E. Learning styles and multiple intelligences in the teachinglearning of Spanish as a foreign language. Enseñanza \& Teaching, v. 33, n. 2, p. 79-103, dez. 2015. doi: http://dx.doi.org/10.14201/et201533279103. Acesso em: 18 out.2019.

LUENGO GONZÁLEZ, R.; GONZÁLEZ GÓMEZ, J. J. Relação entre estilos de aprendizagem, desempenho em matemática e a escolha de disciplinas eletivas em estudantes do ESO. Revista Electrónica de Pesquisa e Avaliação Educacional, v. 11, n. 2, 2005. Disponível em: http://www.uv.es/RELIEVE/v11n2/RELIEVEv11n2_4.htm. Acesso em: 18 out. 2019.

MARTÍNEZ, N. R. Influencia de la inteligencia emocional en los estilos de aprendizaje predominantes de los alumnos de bachillerato de la modalidad de Artes. Educatio Siglo XXI, Murcia, v. 33, n. 2, p. 53-77, 2015. doi: https://doi.org/10.6018/j/232691. Acesso em: 18 out. 2019.

MARTÍNEZ-SANDOVAL, G. et al. Learning styles and types of multiple intelligences in dental students in their first and tenth semester. Journal of Oral Research, Monterrey, Mexico, v. 5, n. 3, s.1, p. 103-107, abr. 2016. doi: https://doi.org/10.17126/joralres.2016.023. Acesso em: 18 out. 2019.

MUÑOZ, H. E. Toledo et al. Evaluación de los intereses de $7^{\circ}$ y $8^{\circ}$ año de enseñanza básica y $1^{\circ}$ y $2^{\circ}$ año de educación media de la provincia de Llanquihue. Journal for Educators, Teachers and Trainers, v. 2, p. 39-48, 2011. Disponível em: <http://jett.labosfor.com/index.php/jett/article/view/16/16>. Acesso em: 18 out. 2019.

NOGUEIRA, D. R. Desempenho acadêmico x estilos de aprendizagem segundo HoneyAlonso: uma análise com alunos do curso de Ciências Contábeis. Revista Espaço Acadêmico, Maringá, v. 12, n. 137, p. 80-89, out. 2012. Disponível em: $<$ http://periodicos.uem.br/ojs/index.php/EspacoAcademico/issue/view/672>. Acesso em: 18 out. 2019.

ORELLANA MANRIQUE, O. et al. Regimes positivos de pensamento de autodialogue estilos negativos e de aprendizagem em alunos university. Revista de Investigacion en Psicologia, v. 12, n. 2, jul. 2009. Disponível em: <https://www.researchgate.net/publication/ 46062266_Esquemas_de_pensamiento_de_autodialogo_positivo_y_negativo_y_estilos_de _aprendizaje_en_estudiantes_universitarios>. Acesso em: 18 out. 2019.

PACHECO RIOS, R.; MALDONADO MALDONADO, E. Relación entre los estilos de aprendizaje y las teorías de enseñanza. Retos: nuevas tendencias en educación física, deporte y recreación, v. 32, p. 7-13, $2017 . \quad$ Disponível em: < https://pdfs.semanticscholar.org/a2d2/52ef8c99339c44421df80db5ded6ab5ad3c1.pdf>. Acesso em: 18 out. 2019.

PORTILHO, E. et al. Brasil e Portugal. A voz do professor: da narrativa à prática - um caso português. Revista Lusófona de Educação, Lisboa, v. 33, n. 33, 2016. Disponível em: $<$ https://search.proquest.com/docview/1846494355?accountid=43603 $>$. Acesso em: 18 out. 2019.

PORTILHO, E. M. L. Aprendizaje Universitario: un enfoque metacognitivo. 2003. 346 f. Tese (Doutorado) - Universidad Complutense de Madrid, Madrid, 2003. Disponível em: <https://eprints.ucm.es/4871/1/T27286.pdf>. Acesso em: 10 ago. 2019. 
PORTILHO, E. M. L.; MATTTOS, H. M. Z. H. de; CRUZ, J. B. A. O desafio de pesquisar a educação infantil: limites e possibilidades. Revista Diálogo Educacional, v. 11, n. 32, p. 123 142, 2011. Disponível em: <https://periodicos.pucpr.br/index.php/dialogoeducacional/ article/view/4096/4015>. Acesso em: 18 out. 2019.

RETANA, J. Á. G. Reflections on learning styles and calculus learning in engineering majors. Actualidades Investigativas en Educación, San José, v. 13, n. 1, p. 362-390, abr. 2013. Disponível em: <http://www.scielo.sa.cr/scielo.php?script=sci_arttext\&pid=S140947032013000100014\&lng=en\&nrm=iso >. Acesso em: 18 out. 2019.

RODRIGUEZ, P. D. O. Diagnóstico de la enseñanza de la estadística utilizando el método del aprendizaje autónomo y significativo. Revista Logos Ciencia \& Tecnología, Colômbia, v. 6, n. 2, p. 218-226, nov. 2015. doi: http://dx.doi.org/10.22335/rlct.v6i2.101. Acesso em: 18 out. 2019.

SILVA, P. M. M. da. Autorregulação da aprendizagem do aluno: uma análise das práticas pedagógicas desenvolvidas por professores do ensino médio de um colégio particular do municipio de Londrina. 2015. 144 f. Dissertação (Mestrado em Educação), Universidade Estadual de Londrina, Londrina, 2015. Disponível em: <http://www.bibliotecadigital.uel.br/document/?code= vtls000204587>. Acesso em: 20 maio 2019.

TORRES, P. L.; PORTILHO, E. L. Projeto MATICE: pretexto para a discussão dos estilos de aprendizagem dos professores. Revista Diálogo Educacional, Curitiba, v. 4, n. 12, p. 157-168, maio/ago. 2004. Disponível em: <http://www2.pucpr.br/reol/pb/index.php/ dialogo?dd1 $=626 \& d d 99=$ view \&dd98=pb>. Acesso em: 18 out. 2019.

VALDEZ, L. R. V. de et al. Estilos de aprendizaje y rendimiento académico en estudiantes de enfermería de una universidad pública de Paraguay. NURE Investigación, v. 16, n. 102, set. 2019. Disponível em: <http://www.nureinvestigacion.es/OJS/index.php/nure/article/ view/1762/890>. Acesso em: 18 out. 2019.

VÁZQUEZ, M. de J. A.; DÖRFER, C.; CORPUS, R. C. Academic Progress Depending on the Skills and Qualities of Learning in Students of a Business School. Turkish Online Journal of Educational Technology - TOJET, v. 14, n. 3, p. 1-8, 2015. Disponível em: $<$ https://search.proquest.com/docview/1720057296?accountid=43603>. Acesso em: 18 out. 2019.

VILLALBA, N. L.; MARTINEZ, A. G. Second language learning styles and sequential bilingual instruction in primary, secondary and university education: toward a state of the art. Lenguage, Cali, v. 42, n. 2, p. 291-314, dez. 2014. Disponível em: $<$ http://www.scielo.org.co/scielo.php?script=sci_arttext\&pid=S0120-34792014000200004\&lng=en\&nmm=iso>. Acesso em: 18 out. 2019.

RECEBIDO: 30/11/2019

APROVADO: $20 / 02 / 2020$

RECEIVED: $11 / 30 / 2019$

APPROVED: 02/20/2020

RECIBIDO: $30 / 11 / 2019$

APROBRADO: 20/02/2020 